\title{
FATORES QUE CONTRIBUEM PARA O DESMAME PRECOCE
}

* Fernanda Davanzo Fadul

* Luciana Ferreira Xavier

ReBEn/10

Fadul F. D. e Colaboradora - Fatores que Contribuem para o Desmame Precoce. Rev. Bras. Enf.; RS. 36: 213 - 220, 1983.

\section{RESUMO}

Durante os estágios realizados em dois Centros de Saúde de Ribeirão Preto, Estado de São Paulo, como parte do curso de Habilitação em Saúde Pública, 60 mães foram entrevistadas, visando conhecer a situação do aleitamento materno entre a população servida por aquelas instituições. As autoras observaram que muitas mães não levavam adiante o aleitamento de seus filhos. Frente a esta problemática, decidiram fazer um levantamento para detectar os fatores que contribuem para o desmame, e partindo daí, apresentam e discutem os resultados encontrados.

\section{INTRODUÇÃO}

No campo de estágio que abrangeu dois Centros de Saúde do município de Ribeirão Preto no estado de São Paulo - participou-se de uma série de atividades: atendimento de enfermagem, suplementação alimentar, vacinação, coleta de material e consulta médica. Todas essas atividades foram trabalhadas de forma integrada com a equipe que atua profissionalmente no local.

Participou-se neste processo também com o intuito de orientar, esclarecer as dúvidas e incentivar a amamentação, embora muitas vezes, deparou-se - através do relato das mães - com o fato de ser grande o número das mesmas que não conseguem levar adiante o aleitamento materno de seus filhos.

Desde o início da vida do ser humano, um dos fatores de primordial importância é o acesso a uma nutrição básica. Esta alimentação eficiente pode ser conseguida na prática do aleitamento materno. Constata-se que tal forma de alimentação caiu em desuso e encontra-se em franca decadência, agravando cada vez mais o problema da desnutrição infantil e conseqüente aumento do índice de mortandade nesta faixa etária $(2,5)$.

No Brasil o número de mães que amamenta seus bebês tem diminuido acentuadamente, e como afirma Cunha ${ }^{(6)}$, "isso é devido a uma peculiaridade brasileira, onde o país é afetado pelo que há de pior nos dois mundos: os grupos sociais rurais, neo-urbanos e de menor renda estão aderindo cada vez mais aos hábitos das pessoas de categoria social mais elevada e diminuindo o hábito de lactância natural. Ao mesmo tempo, os citadinos que estão "por cima' não estão voltando ao aleitamento materno".

"Em estudo realizado pelo Instituto de Pesquisas Econômicas e pelo Instituto de Medicina Preventiva, sobre a situação nutricional de crianças paulistas entre (6) seis a (60) sessenta meses de idade, revelou uma associação significativa entre o aleitamento materno e desnutrição de crianças até 2 (dois) anos de idade. O mesmo foi confirmado em estudo realizado por Puffer e Serrano para a OMS sobre treze projetos latino-americanos, incluindo São Paulo, Ribeirão Preto (sul) e Recife (nordeste)"(6).

Os estudos sobre o aleitamento materno apresentam um conteúdo que, basicamente, realça a superioridade biológica da amamentação como forma de nutrir crianças, e o declínio na sua utilização e duração trazem resultados nefastos para a saúde e efeitos adversos sobre a economia familiar e nacional. $(8,9,11,13,17)$

Neste trabalho pretende-se apresentar e discutir as experiências tidas com as alunas do 4.0 ano de Habilitação de Enfermagem em Saúde Pública, visando a uma identificação dos fatores que interferem na prática do aleitamento materno, ou seja, o desmame precoce.

\footnotetext{
* Alunas do 4. ano de Habilitação de Enfermagem de Saúde Pública da Escola de Enfermagem Ribeirão Preto - U. S. P.
} 
Fadul F. D. e Colaboradora - Fatores que Contribuem para o Desmame Precoce. Rev. Bras. Enf.; RS. 36: $213-220,1983$.

\section{METODOLOGIA}

Realizou-se levantamento em dois Centros de Saúde do município de Ribeirão Preto, através de entrevista, conforme roteiro anexo (1).

Neste foram entrevistadas $(60)$ sessenta mães cujos filhos apresentavam idade entre $(0)$ zero a (24) vinte e quatro meses, matriculados no Programa Materno Infantil, e que estivessem presentes no horário das 7 h e 30 min às 11 e 30 min de $2^{\text {a }}$ a $6^{\text {a }}$ feira, independente do tipo de assistência necessitada.

\section{RESULTADOS}

A análise do roteiro (anexo I), a que as sessenta (60) mães entrevistadas foram submetidas, mostra os seguintes resultados:

TABELA 1 - Idade das crianças segundo época do desmame.

\begin{tabular}{|c|c|c|c|c|c|c|c|c|c|c|c|c|}
\hline \begin{tabular}{|r|} 
EPOCA DO \\
DESMAME \\
Idade \\
das criançaș \\
\end{tabular} & $0 \nrightarrow 1$ & $1 \dashv 3$ & $3 \dashv 5$ & $5 \dashv 7$ & $7 \dashv 9$ & $9 \dashv 11$ & $11 \dashv 13$ & $13 \dashv 15$ & $15 \dashv 17$ & $>17$ & $\begin{array}{l}\text { ESTA } \\
\text { AMAM. }\end{array}$ & QTDE \\
\hline até 1 mês & 1 & & & & & & & & & & 3 & 4 \\
\hline $1-3$ & 7 & & & & & & & & & & 3 & 10 \\
\hline $3 \dashv 5$ & 2 & 2 & & & & & & & & & & 4 \\
\hline $5 . \dashv 7$ & 3 & 2 & 1 & & & & & & & & 1 & 7 \\
\hline $7 \dashv 9$ & 2 & 1 & & & & & & & & & 1 & 4 \\
\hline $9 \dashv 11$ & 4 & 3 & & & & & & & & & & 7 \\
\hline $11 \dashv 13$ & 6 & 5 & & & 1 & 1 & & & & & 2 & 15 \\
\hline $13 \dashv 15$ & & & 1 & & 1 & & 1 & & & & & 3 \\
\hline $15 \dashv 17$ & 1 & & 1 & & 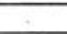 & & & & & & & 2 \\
\hline $17 \dashv 19$ & 2 & & & & & & & & & & & 2 \\
\hline $19 \dashv 21$ & 1 & & & & & & & & 1 & & & 2 \\
\hline TOTAL & 29 & 13 & 3 & 0 & 2 & 1 & 1 & 0 & 1 & - & 10 & 60 \\
\hline
\end{tabular}

Aqui procurou-se verificar o que ocorre em relação ao desmame e foi identicado que:

$42(70 \%)$ setenta por cento das mães entrevistadas cessaram o processo de aleitamento nos primeiros (3) três meses de idade da criança.

A época do desmame mais tardio $1(1,6 \%)$ alcançou o período de (15) quinze a (17) dezessete meses.

Do total das crianças incluídas no estudo, as de idade mais avançada estavam situadas entre os (19) dezenove e (21) vinte e um meses.

No tocante à idade das mães, esta variou entre os quinze e (50) cinqüenta anos.

TABELA 2 - Época do desmame segundo o grau de instrução.

\begin{tabular}{|c|c|c|c|c|c|c|c|c|c|c|c|c|}
\hline $\begin{array}{c}\text { ÉPOCA DO } \\
\text { DESMAME } \\
\text { Idade } \\
\text { das criancasi }\end{array}$ & $0 \dashv 1$ & $1 \dashv 3$ & $3 \dashv 5$ & $5 \dashv 7$ & $7 \dashv 9$ & $9 \dashv 11$ & $11 \dashv 13$ & $13 \dashv 15$ & $15 \dashv 17$ & $>17$ & ESTÁ & QTDE. \\
\hline Analfabeto & 3 & 1 & 2 & & 1 & & & & & & AMAM. & 8 \\
\hline l. Grau $^{2}$ & 14 & 6 & 1 & & 1 & 1 & & & 1 & & 5 & 29 \\
\hline $2^{\circ}$ Grau & 11 & 6 & & & & 1 & 1 & & & & 3 & 21 \\
\hline Universiário & 1 & & & & & & & & & & 1 & 2 \\
\hline TOTAL & 29 & 13 & 3 & - & 2 & 1 & 1 & - & 1 & - & 10 & 60 \\
\hline
\end{tabular}

Na TABELA 2 pode ser notado que:

$8(13,3 \%)$ das mães eram analfabetas

$29(48,3 \%)$ cursaram o primeiro grau

$21(35,0 \%)$ cursaram o segundo grau

$2(3,3 \%)$ cursaram a universidade

E ainda, esta mesma tabela, evidencia que as mães que cursaram o primeiro e o segundo grau desmamaram seus filhos mais precocemente que as demais. 
Fadul F. D. e Colaboradora - Fatores que Contribuem para o Desmame Precoce. Rev. Bras. Enf.; RS. 36: 213 - 220, 1983.

TABELA 3 - Época do desmame segundo a procedência.

\begin{tabular}{|c|c|c|c|c|c|c|c|c|c|c|c|c|}
\hline 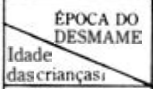 & $0 \dashv 1$ & $1 \dashv 3$ & $3 \dashv 5$ & $5 \dashv 7$ & $7 \dashv 9$ & $9 \dashv 11$ & $11 \dashv 13$ & $13 \dashv 15$ & $15 \dashv 17$ & $>17$ & $\begin{array}{r}\text { ESTÁ } \\
\text { AMAM. }\end{array}$ & TOTAL \\
\hline $\begin{array}{c}\text { Zona } \\
\text { Urbana }\end{array}$ & 26 & 12 & 2 & & & & 1 & & 1 & & 9 & 51 \\
\hline Zona Rural & 3 & 1 & 1 & & 2 & 1 & & & & & 1 & 9 \\
\hline TOTAL & 29 & 13 & 3 & 0 & 2 & 1 & 1 & 0 & 1 & 0 & 10 & 60 \\
\hline
\end{tabular}

Na TABELA 3 pode ser observado que: bana, isto é:

$\mathrm{O}$ desmame até o (3.) terceiro mês incide, na sua maioria, na população residente na área ur-

$$
\begin{aligned}
& 51(74,5 \%) \text { - área urbana. } \\
& 9(44,4 \%) \text { - área rural. }
\end{aligned}
$$

\begin{tabular}{|c|c|c|c|c|c|c|c|c|c|c|c|c|}
\hline $\begin{array}{l}\text { Tipo de } \\
\text { Informaçāo } \\
\text { Sobre aleitamento। } \\
\text { DESMACA DO }\end{array}$ & $0 \dashv 1$ & $1 \rightarrow 3$ & $3 \rightarrow 5$ & $5 \rightarrow 7$ & $7 \dashv 9$ & $9 \dashv 11$ & $11 \dashv 13$ & $13 \dashv 15$ & $15 \dashv 17$ & $>17$ & $\begin{array}{c}\text { ESTA } \\
\text { I AMAM. }\end{array}$ & Total \\
\hline $\begin{array}{l}\text { Curso para } \\
\text { Gestante }\end{array}$ & 8 & 5 & & & & & 1 & & & & 3 & 17 \\
\hline \begin{tabular}{c|} 
No decorrer das \\
Consultas Pré-Natal
\end{tabular} & - & - & - & - & - & - & - & - & - & - & - & - \\
\hline $\begin{array}{l}\text { Orientação do } \\
\text { Pediatra }\end{array}$ & 2 & & & & & & & & & & 1 & 3 \\
\hline $\begin{array}{c}\text { Equipe de } \\
\text { Enfermagemlno Hospital }\end{array}$ & 2 & 1 & 1 & & & & & & & & 1 & 5 \\
\hline $\begin{array}{c}\text { Centro de Saúde } \\
\text { Através do Atendimento } \\
\text { Enfermagem }\end{array}$ & 1 & 1 & & & 1 & 1 & & & & & & 4 \\
\hline $\begin{array}{c}\text { Rádio, T.V., } \\
\text { Parentes e Amigos }\end{array}$ & 2 & 2 & 1 & & & & & & 1 & & & 6 \\
\hline $\begin{array}{c}\text { Nunca Obteve } \\
\text { Nenhuma Informação }\end{array}$ & 14 & 4 & 1 & & 1 & & & & & & 5 & 25 \\
\hline TOTAL & 29 & 13 & 3 & 0 & 2 & 1 & 1 & 0 & 1 & 0 & 10 & 60 \\
\hline
\end{tabular}

TABELA 4 - Época do desmame seguindo tipo de informação

Na TABELA 4 fez-se uma subdivisão em itens de 1 a 7; itens referente ao tipo de informação sobre o aleitamento, afim de melhor interpretação dos resultados e posterior comentário.

Eles são:

\section{CURSO PARA GESTANTES}

Averiguou-se que $17(28,3 \%)$ das mães freqüentaram este tipo de curso, sendo que $13(76,4 \%)$ desmamaram seus filhos até o final do primeiro trimestre.

2. DECORRER DAS CONSULTAS PRÉ-NATAL

Obteve-se, aqui, o percentual zero quanto a orientação sobre aleitamento materno.

3. ORIENTAÇÃO DO PEDIATRA

Apenas $3(5,0 \%)$ das mães receberam este tipo de informação. $2(66,6 \%)$ destas cessaram o aleitamento materno até o (3.) terceiro mês.

4. EQUIPE DE ENFERMAGEM NO HOSPITAL

Das mães entrevistadas $5(8,3 \%)$ receberam informação pela equipe. $3(60,0 \%)$ destas atingiram somente até o (3.) terceiro mês.

\section{CENTRO DE SAÚDE ATRAVÉS DO ATENDIMENTO DE ENFERMAGEM}

Do total da população citada, $4(6,6 \%)$ obteve orientação acerca do aleitamento materno neste serviço de saúde e $2(50,0 \%)$ destas não levaram além do (3\%) terceiro mês este processo.

\section{RÁDIO, TELEVISÃO, PARENTES E AMIGOS}

Verificou-se que $6(10,0 \%)$ das mães estiveram inseridas neste tipo de informação, sendo que $4(66,6 \%)$ destas cessaram a amamentação até o $\left(3^{\circ}\right)$ terceiro mês.

\section{NUNCA OBTEVE NENHUMA INFORMAÇÃO}

Do total de mães entrevistadas, $25(41,6 \%)$ está concentrada na faixa das que nunca receberam nenhuma informação sobre o aleitamento, e 18 (72,0\%) destas desmamaram seus filhos até o primeiro trimestre. 
Fadul F. D. e Colaboradora - Fatores que Contribuem para o Desmame Precoce. Rev. Bras. Enf.; RS. 36: $213-220,1983$.

TABELA 5 - Época do desmame segundo a causa.

\begin{tabular}{|c|c|c|c|c|c|c|c|c|c|c|}
\hline 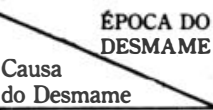 & $0 \rightarrow 1$ & $1 \rightarrow 3$ & $3 \rightarrow 5$ & $5 \dashv 7$ & $7 \rightarrow 9$ & $9 \dashv 11$ & $11 \dashv 13$ & $13 \dashv 15$ & $15 \rightarrow 17$ & $>17$ \\
\hline "Não tinha leite" & 3 & 2 & & & & & & & & \\
\hline $\begin{array}{l}\text { "Leite diminuiu e } \\
\text { secou" }\end{array}$ & 16 & 10 & 2 & & & & & & & \\
\hline $\begin{array}{c}\text { "Criança chorava } \\
\text { muito" }\end{array}$ & 3 & 1 & & & & & & & & \\
\hline "Fome" & 1 & 1 & 1 & & & & & & & \\
\hline $\begin{array}{l}\text { "Criança grande } \\
\text { demais para ser } \\
\text { amamentada" }\end{array}$ & & & 1 & & 2 & 1 & & & & \\
\hline $\begin{array}{l}\text { "Uso de } \\
\text { mamadeira" }\end{array}$ & 4 & 2 & 1 & & & & & & & \\
\hline $\begin{array}{l}\text { "Internação da } \\
\text { criança" }\end{array}$ & 2 & 2 & 1 & & 1 & & & & & \\
\hline "Seio rachou" & 2 & & & & & & & & & \\
\hline "Mãe nervosa" & 1 & 1 & 1 & & & & & & & \\
\hline $\begin{array}{l}\text { "Trabalho fora } \\
\text { do lar" }\end{array}$ & - & 1 & & & & & & & & \\
\hline $\begin{array}{l}\text { "Uso de anti- } \\
\text { concepcional" }\end{array}$ & 2 & 1 & & & & & & & & \\
\hline "Gravidez" & & & & & & & 1 & & 1 & \\
\hline
\end{tabular}

* Opiniões múltiplas de 60 mães.

A TABELA 5 serviu para evidenciar, no estudo aplicado, as causas apresentadas pelas mães para uma justificativa ao fato de não ter dado continuidade ao aleitamento materno; que por ordem de freqüência podem ser assim classificadas:

1. "leite diminuiu e secou"

2. "uso da mamadeira"

3. "não tinha leite" e internação da criança.

4. "A criança chorava muito" e "A criança grande demais para ser amamentada".

5. "fome" mãe nervosa e uso de anticoncepcionais

6. gravidez

7. existência de um trabalho fora do lar.

\section{DISCUSSÃO}

No levantamento realizado, os objetivos principais foram o de conhecer alguns indicadores (consultar tabelas de 1 a 5) que fornecessem uma visão mais ou menos globalizada de uma população de nutrizes residentes em bairros periféricos de Ribeirão Preto, Estado de São Paulo, em relação ao problema do desmame precoce e suas possíveis causas. Os resultados referem-se ao material coletado nas entrevistas.

Outra meta a ser alcançada seria a de fornecer subsídios para levantamentos futuros.

Numa análise mais geral no material estudado foi observado por exemplo: a desinformação das nutrizes a respeito do assunto. É muito comum e parece ser um elemento de maior importância no surgimento do abandono do aleitamento. Fatores concorrentes seriam - de acordo com a analisado na TABELA 4 - o total desconhecimento do fato.

Observou-se ainda uma outra face que foi a comprovação da ineficiência dos cursos oferecidos para as gestantes, talvez decorrente da existência de uma deficiente comunicação verbal dos orientadores ou também a existência de desinteresse das gestantes.

Agravando o problema, surgem outros como por exemplo os ligados ao grau de instrução 
Fadul F. D. e Colaboradora - Fatores que Contribuem para o Desmame Precoce. Rev. Bras. Enf.; RS. 36: $213-220,1983$.

(TABELA 2), quando nota-se que, paradoxalmente, a época do desmame é até mais precoce no grupo de mães com instrução até o $1^{\circ}$ e $2{ }^{\circ} \cdot$ graus.

A carência de orientação dos profissionais da área da saúde é traduzida em vários níveis de atendimento, tais como:

- A consulta pré-natal que poderia ser melhor aproveitada, além do enfoque global sobre a gestante e a criança, um especial preparando a gestante, tanto física como psicologicamente, para o aleitamento.

Rueda(15), ao referir à esse aspecto comenta que: "A consulta pré-natal deveria deixar de ser apenas à rotineira tomada da altura uterina e da pressão, para se tornar, também, uma verdadeira preparação para a amamentação.

Esta atenção médica poderia ser continuada pelos pediatras, pois freqüentemente estes justificam a prescrição do leite industrializado desde o nascimento; observando que o aleitamento ao seio, num meio em que este costume se encontra em franca decadência, não pode ser aprendido da noite para o dia, nem resultar de uma simples recomendação por ocasião da primeira visita do médico ao recém-nascido. Essa recomendação pode suscitar, quando muito, uma respeitosa obediência de pouca duração(15).

A orientação e educação, quanto ao processo de aleitamento natural em indivíduos de ambos os sexos, deveria iniciar-se desde os primeiros anos de escolaridade com o intuito de tornar este princípio mais natural e menos estereotipado e essencialmente ainda nos Centros de Saúde, Hospitais, Ambulatórios, qualquer outra instituição e mesmo no dia a dia de uma comunidade, quando as mães demonstram motivos quaisquer para não amamentar, deveriam os técnicos de saúde ouvi-las - seus argumentos - e orientá-las no tocante a decidir com ınaior segurança o caminho a ser seguido. É importante ressaltar neste momento que: a conscientização das mães deve ser feita com o cuidado de não incutir um sentimento de culpa, caso ocorra o insucesso na amamentação(10).

A grande publicidade existente em torno do leite industrializado, através dos meios de comunicação de massa, conduz uma forma distorcida de informação e atrae a atenção da população afetando de maneira marcante o índice de amamentação ao seio.

Com base no levantamento executado (TABELA 5), várias são as razões apresentadas, pelas mães entrevistadas, para não levar adiante a amamentação de seus filhos.

Pela investigação verifica-se uma origem comum nas dificuldades, pois as diversas respostas convergem para o mesmo fim. Uma reflexão mais profunda sobre o assunto levaria à algumas indagações como:

- Será que as mães foram educadas para o aleitamento?

Elas recebem apoio da sociedade? As leis que favorecem o aleitamento materno realmente vigoram? O papel da mulher-mãe está definido na sociedade? Ela possui lugar seguro e próximo ao seu local de trabalho para poder deixar seu filho e amamentá-lo? Será que o leite distribuído no Centro de Saúde é um incentivo ao desmame?

Seria difícil, dadas as dificuldades do trabalho, apresentar respostas a essas perguntas e, não é esse especificamente o propósito desta investigação.

Dentre as causas citadas pelas mães para o não aleitamento, parecem afirmações não confirmadas ("não tinha leite", "leite diminuiu e secou", "criança chorava muito", "fome", "criança grande para ser amamentada", "uso de mamadeira", "seio rachou") que poderiam estar encobrindo fatores, tais como:

a) aqueles relacionados à estética corporal, pois diversas mulheres pensam que suas mamas se tornarão flácidas e pendentes - caso amamentem seus filhos. Deveria caber aos profissionais o esclarecimento às mães quanto as alterações nas dimensões e turgecência dos seios; uma vez que são associados ao número de gravidezes e à idade e não a amamentação(12).

Como prevenção é indicado o uso de porta-seios que mantenham a mama firme, de preferência de algodão, durante toda a gestação e puerpério. Refere Xavier(16), que na sociedade em que vivemos, a amamentação, aparentemente natural e instintiva, é uma técnica corporal feminina que necessita muitas vezes, de educação e treinamento. Segundo Cunha ${ }^{(6)}$, este problema pode advir da nova auto imagem da "mulher" criada pelos meios de comunicação de massa e pelo meio ambiente.

b) outro fator de relevante importância é a existência de berçários em hospitais. Esta separação mãe-filho pode trazer grande angústia materna, pois a mãe quebra aquele contato de (9) nove meses, e no momento de manter a perfeita interação, a barreira é formada. Os horários das mamadas são pré-estabelecidos de acordo com a rotina hospitalar, deixando a mulher com grande ansiedade durante o intervalo entre uma e outra mamada.

Quanto à tese de que a mãe necessita de descanso, nada é mais tranquilizante para ela do que sentir seu bebê ao lado (mesmo quando chora). Já foi demonstrado, aliás, que o choro da criança é o melhor estímulo para o "reflexo de ejeção" do leite ("let down reflex"), por meio do qual a hipófise an- 
Fadul F. D. e Colaboradora - Fatores que Contribuem para o Desmame Precoce. Rev. Bras. Enf.; RS. 36: $213-220,1983$.

terior secreta oxitocina que contrai as células mioepiteliais perialveolares, permitindo a excreçāo holócrina $(1,7)$; este reflexo psicossomático é inibido pela dor e pela ansiedade (condições favorecidas pelo afastamento do bebê)(15).

E como afirma, ainda, Pernetta(13), se na maternidade for adotado o alojamento conjunto (Rooming-in), como é de toda conveniência, a primeira mamada ocorrerá como um acontecimento natural, quando a criança chorar e a mãe estiver em condições de atendê-la.

c) mais um fator seria o de muitas das mães mostrarem-se francamente estimuladas à aquisição do leite industrializado "grátis", pois de acordo com a sua situação sócio-econômica, muitas vezes torna-se viável, a elas, o desmame precoce, passando a receber o leito do Posto de Saúde, podendo distribuí-lo em parcelas altamente diluídas a todos os membros de sua família, levando a um aumento gradativo da desnutrição infantil.

De acordo com Ciari Júnior(5), a idéia de combater a desnutrição infantil, iniciada a mais de vinte anos, através da distribuição de leite aos lactentes pelo Centro de Saúde, não atingiu os seus objetivos, pois constata-se que não só a desnutrição, em baixa idade aumentou, como também houve um incremento da mortalidade infantil.

No presente trabalho não foram levantados os índices de mortalidade no grupo estudado, mas ficou a impressão que existe uma relação entre a incidência de desmame precoce, acompanhando a distribuição indiscriminada de leite.

d) outro fator ainda seria o uso da mamadeira e que seguindo a mesma análise, contribui para aumentar a taxa de desnutrição e a maior incidência de infecções, ou seja, os elevados preços dos produtos e as deficiências higiênicas do meio em que vivem as populações pobres faz com que as mães forneçam às crianças além de um leite fraco, diluído, de pouco valor nutritivo, um leite altamente contaminado por bactérias. Nesta situação, a opção entre o seio materno e a mamadeira pode representar a escolha entre a saúde e a doença, ou até mesmo entre a vida e a morte ${ }^{(2)}$.

Apontou-se neste estudo outra razão que foi a hospitalização do recém-nascido, por quaisquer motivos, a qual deveria requerer atenção especial da equipe médica e de enfermagem à nutriz, no sentido de incentivá-la a comparecer ao hospital para amamentar o seu bebê, ou mesmo orientá-la quanto à ordenha manual para que o estímulo à amamentação não cesse durante este período de hospitalização.

Notou-se também, apesar do pequeno índice referido como causa, o uso de anticoncepcionais orais, não deve ser esquecido, pois como afirma Choppra ${ }^{(4)}$, os fatos atualmente conhecidos levam a pensar que certos tipos de pílulas anticoncepcionais tem ação inibidora sobre a lactação, sobretudo se contém altas doses de estrógeno e que são administradas logo após o parto antes que o processo da lactação esteja totalmente estabelecido.

Destemodo convém insistir no fato de que, individualmente, o aleitamento nãopode ser considerado um método seguro de contracepção embora em nível comunitário a lactação prolongada redunde em redução global da fecundidade.

Cabe nesta ocasião uma orientaçã̃o a estas mães sobre os vários métodos de anticoncepção que não prejudiquem o aleitamento, pois como já foi provado nos estudos citados acima, não é garantido que a ovulação ocorra neste período.

Finalizando a discussão dos resultados obtidos na TABELA 5, encontrou-se um menor grau de incidência no trabalho fora do lar como causa de abandono ao aleitamento, o qual a nível global representa um grave problema(14), ou seja, a mulher deixa seu espaço familiar e se lança ao mundo, em busca da sobrevivência de sua numerosa prole e dela própria. É de conhecimento que as condições de trabalho da mulher são desfavoráveis à amamentação. Muitas vezes as leis trabalhistas existentes não são obedecidas e porisso não vigoram, ou quando executadas devidamente são em grande parte inaplicáveis pelos seguintes motivos:

- inexistência de creches nos locais de trabalho, ou ao menos perto dos mesmos, sendo assim. a nutriz, que recebe dois descansos especiais de meia hora cada um durante a jornada de trabalho ${ }^{(3)}$ para amamentar, perde grande parte ou todo este tempo no percurso entre o local de trabalho até onde deixou sua criança;

- quando existem creches, o n. de leitos é limitado, não abrangendo a procura; ou ainda em outros casos, o horário de funcionamento das creches não acompanha a jornada de trabalho da mulher.

Embora essas razões possam ser referidas pelas mulheres pesquisadas, representam apenas a superfície do fenômeno analisado seguindo a óptica e a postura dos investigadores.

\section{CONCLUSÃO}

De acordo com o que pôde-se observar, colheu-se as seguintes conclusões:

1. A maioria das mães entrevistadas $(70,0 \%)$ interromperam o processo de aleitamento por volta do (3.) terceiro mês. 
Fadul F. D. e Colaboradora - Fatores que Contribuem para o Desmame Precoce. Rev. Bras. Enf.; RS. 36: $213-220,1983$. to materno.

2. Um grande percentual de mães $(41,6 \%)$ nunca receberam informações sobre o aleitamen-

3. Entre as mães que cursaram o (1.9) primeiro e (2.) segundo grau o índice de desmame precoce foi superior aos demais.

4. As principais causas encontradas foram:

- "leite diminuiu e secou"

- "uso de mamadeiras"

- "não tinha leite" e internação da criança.

\section{SUMMARY}

To know the situation of breastfeeding practice in population served by two Healt Center in Ribeirão Preto, state of São Paulo, Brazil, the authors inteviewed sixty mothers. During the observation period they found in several ocasions a group of mothers that stoped abruptly the breastfeeding. According the results the majors causes appears to be the lack of information about the advantages of natural feeding and also social and instructional problems.

\section{BIBLIOGRAFIA}

1. APPLEBAUM, R.M. citação RUEDA, E.P. Os aspectos Práticos d o aleitamento a o seio - in Anais Nestlé, F-103; 80-89; 1979.

2. BARROS FILHO, A.A. Desmame precoce um problema multinacional - in Debates em Saúde; vol. 45-54.

3. CARRION, V. Comentários à Consolidação das Leis do Trabalho; $15^{\mathrm{a}}$, in Revista dos Tribunais - SP., 215; 1982.

4. CHOPRA, J.G. - citação BARVAZIAN, A.P. Saúde materno infantil e alimentação ao Seio. -in Anais Nestlé - fascículo n. 103-66-77; 1979.

5. CIARI JÚNIOR, C. citação PARETA, J. M. M. Meira, R.A. e D’Andreatta, Jr. C. Saúde da comunidade; McGran - Hill do Brasil; 203-222, 1976.

6. CUNHA, G. Documento para debates - 8016 - Proposta de Estratégia de Comunicação para a promoção do aleitamento Materno no Brasil, in UNICEF, Brasília, abril, 1-66; 1980.

7. ELY, R. Peterson, W.E. citação RUEDA, E.P. Os aspectos Práticos do aleitamento ao seio, in Anais Nestlé, F-103; 80-89, 1979.

8. HARDY, E. F. cols - Programa comunitário de estímulo do aleitamento materno, in A. M. B., vol. 27, n. $10 ; 288-290 ; 1981$.

9. LLORENS, J. Figueras, G.; PICAÑNOL, J. Pediatria para enfermeras, Editorial Jims-Barcelona; $41-49,1972$.

10. MICHELL, H. S. e cols - Nutrição, 16; Interamericana Rio de Janeiro, 244-257; 1978.

11. ORNELLAS, A. \& Ornellas, L. H. Alimentação da criança-nutrição aplicada; Atheneu Editora São Paulo S. A. - P; 265-288; 1970.

12. OSKI, F.A. citação Rueda, E. P. Os aspectos práticos do aleitamento ao seio; in Anais Nestlé, fascículo n. 103, 80-89, 1979.

13. PERNETTA, C. Alimentação da Criança; 7; Fundo Editorial BYK - Procienx; São Paulo; 101 $137,1980$.

14. RAYA, L.C. - Palestra proferida no Congresso da Associação Brasileira,de Juízes de Menores em Fortaleza; outubro de 1981.

15. RUEDA, E. P. Os aspectos práticos do aleitamento a o seio; in Anais Nestlé; F-103; 80-89, 1979.

16. XAVIER, R. F. A técnica corporal: amamentação (comunicação pessoal).

17. WAECHTER, E. H.; BLAKE, F. G.; LIPP, J. P. Enfermaria Pediátrica; 4; Nueva Editoral Interamericana S.A. de C. V.; 1978. 
Fadul F. D. e Colaboradora - Fatores que Contribuem para o Desmame Precoce. Kev. Bras. Enr.; RS. 36: 213 - 220, 1983.

\section{ANEXO I}

ROTEIRO DE ENTREVISTA

Crianças 0 a 24 meses

1) NOME DO LACTENTE

2) NOME DA MÃE

3) IDADE ................... MÃE

4) GRAU DE INSTRUÇÃO DA MÃE

5) PROCEDÊNCIA: zona rural $\ldots \ldots \ldots \ldots \ldots \ldots \ldots$ zona urbana

6) TEVE ALGUMA INFORMACุÃO SOBRE O ALEITAMENTO? ATRAVÉS DE QUE MEIOS?

7) TIPO DE ALEITAMENTO:

natural artificial misto $\square \longrightarrow$ a partir de que mês?
$\square \longrightarrow$ por que? 